\title{
Pharmacokinetic Parameter Category
}

National Cancer Institute

\section{Source}

National Cancer Institute. Pharmacokinetic Parameter Category. NCI Thesaurus. Code C87977.

A classification of pharmacokinetic parameter data. 